\section{DE DE GRUYTER} OPEN G

\author{
Zofia Patora-Wysocka*
}

University of Social Sciences
Journal of Intercultural Management

Vol. 6, No. 4, December 2014, pp. 233-243

DOI 10.2478/joim-2014-0048

\title{
Barriers to New Practice Emerging
}

\begin{abstract}
The article discusses the issues of barriers to creating practice from the processual perspective in management sciences. The notion of practice is a relatively important cognitive concept in the processual approach to management. It is connected with the issues of the organizational change and draws on Anthony Giddens's concept of structuration. Management issues understood in this way are presented in the context of the specific nature of enterprises' functioning as part of their everyday actions. This article is a theoretical and empirical analysis of the issues discussed. The goal of the research is to recognize barriers to emerging practice in an enterprise. The researcher used qualitative methods. As part of this research, a semi-structured interview was conducted in an enterprise representing the textile and clothes sector. Barriers to practice development are of processual, resource and environmental character. The most important barriers to practice creation are those which are sector-specific and environmental.
\end{abstract}

Key words: barriers, practice, routines, actions, emerging practice

Acknowledgements: The paper was prepared as part of a project financed by the National Science Centre, grant no. DEC-2011/03/D/HS4/01651.

\section{Introduction}

This article is a theoretical and empirical analysis of the issues concerning barriers to creating practice from the processual perspective in management. The concept of practice plays an important role in the processual trend in management. This current promotes a functional approach to the organization and management processes. It refers to the works of practice theorists and evolutionists, and draws

\footnotetext{
*zpatora-wysocka@spoleczna.pl
} 
on the thought of Anthony Giddens (1984), Bourdieu (2005), Nelson and Winter (1982). Within the processual current, processes and management change can be perceived from the micro-cognitive perspective, in the case of which significant cognitive categories are managerial and strategic activity, practice and practices (Jarzabkowski, 2005), and routines (Feldman, Pentland, 2003). In this context, it refers to actions carried out daily, while when understood empirically, it is based on observation of the specific character of business functioning as part of its everyday processes. The concept of practice is cognitively useful, as it draws on the theory of structuralization by Anthony Giddens [1984], the processual approach and the interpretative trend in management (Sułkowski, 2012; Jarzabkowski, 2005; Weik, 2000). An important aspect of issues associated with the change of practice is the concept of the change of routines, which is clearly inspired by the evolutionary approach (Nelson, Winter, 1982). This research aspect, analysed by such scholars as Gilbert (2005) and Moorman and Miner (1997), puts particular emphasis on exploring the issues of routines and the routinization process. The goal of this article is to present and consolidate a relatively new cognitive perspective in management in reference to the issues of barriers in change management. The concept of barriers to change is well-known in the subject literature, however, it can be said that an attempt to analyse this problem from the processual perspective will be a novelty in the practice and theory of management. An attempt at observing the barriers to new practice emerging is associated with an analysis of the specific character of functioning from the angle of everyday actions - seemingly unimportant events and processes that can determine the development of an enterprise, adaptation to ongoing changes and implementation of innovative solutions. The first, theoretical part of the article presents the main concepts that are important for the issue of barriers to creating new practice. The second part is an attempt at an empirical illustration of the approach used. The methods applied in the research were qualitative (an in-depth interview). The summary describes barriers to a new practice emerging from the processual perspective, and points out the cognitive usefulness of such an approach.

\section{Institutionalization of practice}

Institutions are the most durable categories of social order and, according to Anthony Giddens, their nature is functional, i.e. their durability is associated with their reproduction (1984). A. Giddens's structuration theory focuses on practice understood, above all, as day-to-day routines and activities (Giddens, 1984: 364). Institutionalization is a process of consolidating social categories that can be related to organization, organizational behaviour (Olivier, 1992), institutionalized practices and traditions (Dacin, Dacin, 2012: 330). Pamela Haunschild and David Chandler place institutionalization in the context of business practice and associate 
it with the process of new practices' diffusion through population and organizational learning (Haunschild, Chandler, 2012: 624-649). Institutionalization can be carried out by means of planned activities, but it can also be a result of spontaneous actions (Patora, accepted for review, 2015). The concept of unplanned actions in strategic management is not new. It was already discussed in a path-breaking work of James March, who coined the term of boundedly rational action in the decision-making process (March, 1988). Those concepts become even more important in the modern external environment, which is complex and unpredictable. In such circumstances, strategic actions are taken quickly and spontaneously, while from the perspective of strategy, as Karl Weik (2000) emphasizes, significance and strategic symbolism are often linked to those events which could not have been planned, but, in spite of everything, brought positive results. It can be said that such spontaneous, yet intentional actions are characterized by certain logic, which is specific for a given enterprise and results from various factors such as shared understanding (Shau et.al, 2009: 31), learning processes (Polanyi, 1958), historical patterns of activity and routinization (Lazaric, 2010). Spontaneous actions can be institutionalized as reproduced practice. Going back to Giddens, reproduction of day-to-day actions is at the core of the social reproduction process (Giddens, 1984: 17). Then the routinization process takes place (Lazaric, 2010). Organizational routines allow for maintaining the processual continuity of an organization and keeping the knowledge as repeatedly reproduced processes. Actions of people within a given organization become a routine, which is subject to the manager's control on the one hand, and the processes of social interaction and self-critical evaluation of people who repeat it on the other hand. Thus, institutionalization takes place, i.e. specific methods of action are consolidated, and then they can be modified. Hence, erosion of the reproduction process is connected to stopping the routine of daily activities, while the lack of reproduction of processes and day-to-day activities can be understood as a fundamental barrier to new practice emerging. Barriers to new practice emerging can be connected to resources or processes, which is discussed in detail later in this work. They can also be associated with resignation of (some part of) previous activity of an enterprise, or be a consequence of staff reduction or changes in the external environment.

\section{Processual and resource barriers to creating practice}

Processual and resource barriers to emerging practices are relatively new cognitive categories in change management. The concept of processual and resource barriers is a development of the concept of Clark Gilbert, who, when studying the process of organizational inertia in enterprises, suggested to analyse the phenomenon from the perspective of resources and processes (Gilbert, 2005). Gilbert coined the term of resource and routine rigidity, and placed it in the context of change 
management. In his research, he pointed out the differences between resource and processual (routine) contexts of inertia, and observed that resource rigidity is easier to overcome than routine rigidity (Gilbert, 2005), as it is easier to take a one-off decision about investment than change the organization in behavioural terms.

Changes of routines are connected with deep and complex functional modifications, which are placed in the historical and cultural contexts of a given organization and people who create it. Routines represent knowledge in the form of repetitively performed actions, but the acquisition of that knowledge is a conscious and reflective process subjected to situational determinants. Therefore, routines may be purposively changed, in a planned or unplanned manner, and used as a platform for the introduction of new modes of action and, by the same token, for the creation of new routines. A change of routines may also meet resistance. Thus, barriers to new practice emerging can be processual and connected to the routinization of actions. Routinization is defined as the recurrence of behaviour patterns in the context of organization learning. Routinization is associated with different levels of procedural knowledge, which facilitates operations, especially in the context of repetitive actions and working within a seasonal cycle. Christine Moorman and Ann $\mathrm{S}$. Miner show that in a situation of moderate or low levels of external turbulence a high degree of procedural knowledge has a beneficial effect on performance in the short term. However, it does not improve creativity or the development of new products or services. The authors also observe that external turbulence can reduce the value of shared (largely procedural) knowledge within organization (Moorman Miner, 1997).

In an unpredictable environment, spontaneous factors, the ability to interpret the information flow and make the most of every opportunity become more important.

\section{Methodology and case selection}

The study presented was based on an in-depth interview with the case selected purposively by what Richard Fenno calls "soaking and poking" (Fenno, 1986). Thus, the researcher had some situated knowledge concerning the studied company and the context in which it operates. This paper presents the case of a company that is affected by some barriers to practice emerging in the seasonal cycle.

A semi-structured interview was conducted according to some general guidelines. It consisted of two parts: the preliminary part characterized the studied enterprise, while the main part addressed the issues of internationalization, collection development, product development, innovation, investment, and the use of new technologies in product development. The methods of gathering data were: an interview, non-participant observation, and document analysis (sample books, folders). The organization of the study: the in-depth interview lasted ninety minutes, when about twenty pages of notes were made, and right after the interview the 
notes were completed. Instructions regarding the interview included the following issues: the enterprise's profile and foreign activity, product's development in the seasonal cycle, the method of work on the product, investment activities, sales planning, and promptness. The interview included an introductory part, where the basic information about the enterprise was established, and the main part, which focused on the research subject. The first part of the interview was conducted with the owner alone, while the second part additionally involved an informant who worked closely with the owner. Another source of data was a brief interview with the third informant - an employee of the knitting facility. The interview was conducted on the 3rd June 2014 at the seat of the enterprise. Data analysis consisted of rewriting the interview based on the notes taken during the interview. The interview was then authorized by the owner of the enterprise. In accordance with Creswell's procedure of qualitative data analysis (Creswell, 2009), the material was read in order to establish the general meaning of the information. Subsequently, the material was coded to determine the main research themes.

\section{Profile of the enterprise}

The examined enterprise has been in the textile and apparel business since 2000 . The enterprise is a family business employing about ten persons. It manufactures women's knitwear, such as sweaters, sleeveless pullovers, vests, and tunics, with sweaters being the leading products. The company has its own, well-equipped knitting and sewing facility, as well as a transport department. The company sells its products in Poland and abroad (mainly to Germany), with most of its production being exported. The company occupies a specific niche in the market, addressing its products to customers representing the conservative group of laggards, according to Rogers's theory of innovation diffusion (Rogers, 1962).

\section{Institutionalization of reproduced practice}

In the textile and apparel industry, it is widely believed that fashion begins with the development of fabrics. This is also true in the case of knitwear. Therefore, a company that owns not only a sewing facility, but also a knitting facility, faces the challenge of designing knitted fabric. The design process is institutionalized - the continuous reproduction of "pattern diversity" is the fundamental area of the company's activity, which is the basis for routinely developed products in a seasonal cycle:

If you have a typical sewing facility, you buy knit fabric. The fabric you buy may be imported or Polish, and depending on the pattern of that fabric you can make, say, a T-shirt, right? A simple, plain T-shirt. And now those patterns... they come with the fabric you buy. But we produce those patterns. Like here (the interviewee presents a knit fabric sample book). The texture and colour and some openwork, the pattern itself, right? Just like this. And these are elements from a knitting machine, like this. And then this is found in the finished element. 
The design process is conducted in-house, based on different sources of inspiration, and also partially contracted out to external freelancers. The company works on the regular basis to increase the variety of garment designs it offers and to improve their aesthetic value. This is a key factor in the industry, as well as the very basis for institutionalization of practice:

I'd say that as regards design, it depends. We have a student, a graduate of the Art School, and she helps us a little. She prepares some drafts in this format, some drawings like that, and suggests something. We also try to do this on our own, based on some knitwear fragments, right?(Owner)

(During the visit to the knitting facility) Knit fabrics of this type come from such plaits. When it comes to designs, there's a student who helps us a little; she also works in the knitting industry. (An employee of the knitting facility).

The owner makes it clear that design is a continuous process of product development as garments and inspirations evolve: patterns from one garment are used on other garments, and they are constantly improved. Design and product development are founded on modernization of the reproduced routines. Routine evolution in the design process remains within the limits defined by the customers' aesthetics:

These knit fabrics may be combined. It may bappen that, for example, you will have some pattern that will be used on others (...) But this is a kind of a stopgap. Primarily, we come up with patterns ourselves. And we are also inspired by, yes, by customers. By the target customer.

\section{New garments/lines in the collection throughout the season versus new practice development}

The studied apparel enterprise works throughout the season. It does not plan for the number of apparel lines to be introduced, which is consistent with the adopted business model. The owner highlights the role of wholesalers in the process of production planning. This planning is short-term (on a weekly basis) and it fits well the cyclical and changing nature of the textile and apparel industry. However, in this case it seems that this volatility concerns lead time and order parameters rather than fashion changes. The lack of a need for new silhouette development is a kind of barrier to new practice development. It results from internal beliefs and bad experiences in this regard. Thus, there is no need to combine routines and capabilities; there is no need to search for new solutions. Once the samples are developed, they form the basis for regularly reproduced actions over a certain period of time. In this context, it is difficult to precisely determine the period over which the processes will be repeated because it depends on the customer and current demand. At the same time, this strategy gives the company a competitive advantage over Chinese companies, which offer much higher minimum order quantities and much longer lead times: 
We work on a weekly cycle. But it's the wholesalers that matter. They simply know what sells well. They come and say: "I'll have this, I won't have that." It's like that: I prepare a collection. I show them a few patterns. So, the idea comes first, the programmer makes a program for the knitting machines. And the machine makes these elements. We take them [to the customer]. The customer takes a look at them and says: "Give me this, give me that, give me this in sizes from $M$ to XXL, or XXXL." So if he likes it, he orders two, three, five bundred units in this or that colour. So, he orders that in four colours across the full size range. Just to give it a try. If this sells well, then he orders more. I'll get him two hundred, next week three or five hundred, and he shows it to his customers who sell it. They have their chain stores and retail it. If it sells well, then more [is ordered]. They call him and he places orders for more: "It's selling well. Give me one, two, three thousand of this," or "Don't because it's not selling well."

We have weekly order cycles. We are very flexible. Our advantage over the Chinese is that in China you have to order sweaters half a year ahead, and order at least one bi-cube container. And you can't be sure whether you're going to make a hit with the colour or the cut. You don't know. And here - two, three, five hundred units, right?

\section{Unusual orders versus processual and resource barriers to new practice development}

The company is flexible in terms of the use of resources (machinery) and the application of technologies. Its business model is based on a weekly cycle. Colours vary greatly. The company can modify the garments it produces and it can change the way its machines are used. Nevertheless, the company does not undertake to carry out unusual orders, which would require a change in the current way of making the product and a new method of using the resources. Thus, in the context of machinery, there are no resource barriers to new practice development:

I can make practically any colour on a weekly cycle. At one point in time, we delivered three versions to Germany: red, maroon, and black-and-white. Black-and-white is the basic thing. Anyway, it is the basic thing even in the Polish market. We did greys and mottled greys, right? Greys and some green. Four years ago those colours were in. Dark lilac, yes, in Poland, too. And basically, this colour has been in for the past four years, but it's started to disappear. As if everyone's fed up with it. Everybody, with this colour, this dark lilac. Now in Poland we have coral red, beige, ecru colours. Some time ago there was mint green. (Owner)

Colours are most problematic. But normally it looks like that: first there's an idea, the programmer prepares the program and the knitting machines start work. (An employee of the knitting facility)

Barriers to new practice emerging are of processual character. Thus, at the same time, the owner voices some doubts as to whether taking unusual orders and producing complicated patterns are worthwhile. On the one hand, this is justified by the limited needs of the laggards. On the other hand, important issues are the profitability of such production and the limited pricing range. Barriers to new practice development are connected to bad experiences in this regard. Difficult, unusual 
orders are not carried out on purpose, as they proved unprofitable in the past:

Generally, we can make anything with the machines we have. The only thing is whether it'll bring profit. We can actually do any style. The only question is whether it'll bring profit. If I'm to put in lots of time working on a complicated pattern and this macbine's going to use up a lot of fabric, if this model's going to be very time-consuming and require many operations, and then it turns out it's not worth the trouble... Maybe if we were a stronger company, if we bad our own chain of stores, then we could perbaps give it a try.

\section{"The Chinese problem" - resource versus external environment barriers to new practice emerging}

From what the owner and the employee said, it may be inferred that the resource barrier (the company does not have a chain of stores) is compounded by external environment pressures for some barriers' development. It is related to the dominant position of Chinese companies and the practices of shopping malls:

At a certain point in time, we were thinking about opening our own chain of stores, but when we saw what was going on - you can just go to shopping malls and see how many strong companies have wound up (...). Stores carry mostly Chinese products. You know, the margins. The prices are so low. The stores have to mark up, like in big shopping centres, like in Manufaktura or Galeria, they have to mark. up, selling sweaters at 70 PLN. And they buy it from the Chinese for 15 PLN. And I have to pay that for the raw material alone (...). Right now the "Made in Italy" products you buy in the shops are Chinese.

The owner believes the "Chinese problem" to be global, affecting the industry in different countries. It is certainly not only a local problem of weak companies. It is a problem that determines sector-specific change, which may be an institutional factor inhibiting internal restructuring change (related to organizations operating in the market, such as shopping malls and Chinese companies). This inhibitor may be difficult to overcome. A company operates under certain external circumstances. Routine change and resource flexibility are important categories of restructuring change. However, they are strongly affected by external determinants. Institutional inhibitors may hinder internal mechanisms initiating restructuring change:

Actually, it's the same thing in Paris. My German friends told me: "Listen, you go to Paris at eight o'clock. You give them a blouse and you pick up 1200, 1000 units in the evening. And that - a new design, new design, new design..."

You should realize that Chinese production is huge now. High quality, too. The colours, the patterns, they are, say, very sophisticated and complicated. These are no longer simple T-shirts. They are sophisticated. Recently, I was shocked to see a Chinese product with rbinestones which had to be manually attached. There are some templates for that, rbinestones, stitches, application methods, die stampings, extrusions, different materials.

The studied enterprise exhibits certain aspects of process inertia in terms of product development in a seasonal cycle (especially as regards the influence of un- 
usual orders on product development) and in terms of its marketing strategy (the company generally does not participate in fairs). The element of resource barriers is linked to the fact that the company does not have its own stores. However, these factors are clearly determined by the external environment inhibitors of change and new practice development. To overcome these inhibitors, it may be necessary to completely remake the business model, develop a brand identity, and deploy marketing communications. At the same time, the currently pursued business model, based on fulfilling orders as they come, and focused on a narrow market segment, proves that the existing business model has been successful up to the moment, but it may be necessary to modify it in the future.

\section{Discussion and Conclusions}

Barriers to new practice development are important elements that should be taken into account when considering change in textile and apparel enterprises. The introduction of products, marketing, and technological changes on a regular basis are essential parts of the business of companies in the fashion industry. Textile and apparel enterprises cyclically reproduce processes and actions, which at the same time determine product changes in the context of fashion trends. Practice of product development is an important element of maintaining process continuity in companies working within a seasonal cycle. This is the process of micro-changes to routinely performed actions in the process of product (collection) development. In reference to works by A. Giddens (1984), and some evolutionists (Nelson, Winter, 1982), one can argue that routines are elementary units that make up and order organizational processes. Changes in an organization and new practice development are primarily initiated at the level of routines. Thus, routines reveal a dual nature: their defining repetitiveness clashes with the tendency to change them by people who consciously reproduce them. This is also an area where mechanisms initiating and inhibiting change to cyclically replicated practices collide. These phenomena affect textile and apparel companies that function in a seasonal cycle, where some routinization is a natural part of their operations.

The most important barriers to new practice development are sector-specific changes and institutional issues embedded in the external environment of the company. These are the most important pressures that may potentially invalidate the profiles of textile and apparel enterprises and their business models.

The company analysed in the case study operates in a very specific niche, in which adaptation to changing fashion is not an element characterizing the customers' needs. Barriers to new practice development are in the very case secondary to the external environment pressures. From the perspective of the population ecology theory (Hannan, Freeman, 1977), changes in an organization are strongly interrelated with changes in the external environment. Sector-specific change in 
the textile and apparel business results in very demanding business conditions. The study has revealed a number of barriers and fundamental elements of adaptation to the specific characteristics of the sector: the right structuring of collections, an appropriate share of fashion products, and operating in line with fashion seasons. At the same time, the case study has indicated that the external environment plays a critical role in the process of continuous restructuring change.

\section{Bibliography}

Bourdieu, P. (2005), The social structures of the economy, Cambridge: Polity Press.

Creswell, J.W. Research design. Qualitative, Quantitative, and Mixed Methods Approaches. 3rd ed. California: SAGE Publications, Inc., 2009.

Dacin, M. T. and Dacin, P.A. (2012), Traditions as Institutionalized Practice: Implications for Deinstitutionalization [in] Organizational Institutionalism, Greenwood, R. and et.al. (ed.), SAGE Publications, 3rd ed., London.

Feldman, M.S. and Pentland, B. Re-theorizing organizational routines as a source of flexibility and change. Administrative Science Quarterly. 2003, Vol. 48, Iss. 1, pp. 94-118.

Fenno, R.F. Observation, Context, and Sequence in the Study of Politics. American Political Science Review. 1986, Vol. 80, Iss 1, pp. 3-15.

Giddens, A. The constitution of society: Outline of the theory of structuration. Berkeley: California University Press, 1984.

Gilbert, C. Unbundling the structure of inertia: Resource versus routine rigidity. Academy of Management Journal. 2005, Vol. 48, No. 5, pp. 741-763.

Hannan, M.T. and Freeman, J. (1977) The population ecology of organizations. American Journal of Sociology. 1977, 82 (5), pp. 929-964.

Haunschild, P. and Chandler, D. (2012) Institutional - Level Learning: Learning as Source of Institutional Change [in] Organizational Institutionalism, Greenwood, R. and et.al. (ed.), SAGE Publications, 3rd ed., London.

Jarzabkowski, P. Strategy as practice. An activity based approach. SAGE Strategy Series. London: SAGE Publications, 2005.

Lazaric, N. Routines and routinization: an exploration of some micro-cognitive foundations [in] Becker, M.C. (ed.), Hanbook of Organizational Routines, Cheltenham, Northampton: Edward Elgar. 2010, pp. 205-227.

March, J. (1988), Decisions and Organizations. Oxford: Blackwell.

Moorman, C. and Miner, A.S. The impact of organizational memory on the new product performance and creativity. Journal of Marketing Research. 1997, Vol. 34, Iss. 1, pp. 91-106.

Nelson, R. and Winter S. An Evolutionary Theory of Economic Change, Cambridge: Harvard University Press, 1982.

Olivier, C. (1992), The Antecedents of Deinstitutionalization, "Organization Studies", 13/4, pp. 563-588. 
Patora-Wysocka, Z. (2015), The institutionalization of spontaneous changes in enterprises: A processual perspective, Journal of Contemporary Management, submitted paper.

Polanyi M. (1958), Personal Knowledge: Towards a Post-Critical Philosophy, University of Chicago Press.

Rogers, E.M. Diffusion of Innovations. Glencoe: Free Press, 1962.

Schau H.J., Muñiz Jr. A.M., Arnould E.J. (2009), How Brand Community Practices Create Value, "Journal of Marketing", Vol. 73, pp. 30-51.

Sułkowski, Ł. (2012), Epistemologia i metodologia zarzadzania, PWE, Warszawa. 